\title{
Gp96-secreting Allogeneic Bladder Cancer Cell Vaccine HS-410
}

National Cancer Institute

\section{Source}

National Cancer Institute. gp96-secreting Allogeneic Bladder Cancer Cell Vaccine HS-410.

NCI Thesaurus. Code C113653.

An allogeneic urothelial bladder cancer cell vaccine expressing a recombinant secretory form of the immunoadjuvant heat shock protein gp96 fused with an immunog lobulin Fc domain (gp96-Ig) protein, with potential antineoplastic activity. Upon administration of the gp96-Ig-secreting allogeneic bladder cancer cell vaccine HS-410, the live, irradiated tumor cells continuously secrete gp96-Ig along with its chaperoned tumor associated antigens (TAAs). This enhances antigen cross presentation to cytotoxic T-lymphocytes (CTLS) and, upon expansion, leads to the induction of a potent $C T L$ response against the TAAs on the endogenous bladder cancer cells. This vaccine also induces a memory $T$ cell response that could fight recurring cancer cells. gp96-Ig is constructed by replacing the KDEL endoplasmic reticulum (ER) retention sequence of gp96 with the Fc portion of the IgG1 protein. This allows for gp96, normally an ER-resident chaperone peptide, to be released from cells. 